\title{
Development and Performance Evaluation of an Engine Operated Mower
}

\author{
Merga Workesa Dula, Solomon Lamessa Kereyu \\ Oromia Agricultural Research Institute, Bako Agricultural Engineering Research Center, Agricultural Machinery and Farm Power \\ Engineering, Bako, Ethiopia \\ Email address: \\ mergaw180@gmail.com (M. W. Dula), mworkesa@yahoo.com (M. W. Dula), kennakereyu@gmail.com (S. L. Kereyu) \\ To cite this article: \\ Merga Workesa Dula, Solomon Lamessa Kereyu. Development and Performance Evaluation of an Engine Operated Mower. American \\ Journal of Mechanical and Materials Engineering. Vol. 5, No. 3, 2021, pp. 39-43. doi: 10.11648/j.ajmme.20210503.11
}

Received: September 23, 2021; Accepted: October 19, 2021; Published: October 30, 2021

\begin{abstract}
Unquestionably, Ethiopia is still taking the primary place in its livestock resource impending compared African countries. Nonetheless, due to numerous motives the nation has yet subjugated from its commercial likely for years. Although, much of the forage produced in the country is harvested directly by grazing animals, a small portion is manually harvested and carried to the animal. The main of the work was developing and evaluating performance of an engine operated mower which is pushed manually in field. The developed rotary mower has three wheels, two front wheels and one rear wheel. The rear wheel was used for steering at the end of farm land. The pulley on an engine was connected to the pulley shaft carrying blade and the vertical rotation on the engine converted in to horizontal on the blade by twisting the belt. This mower is used to reduce the charge and power requirement for domestic perseverance. This mower is fabricated using locally obtainable material and spare parts and thus, it is effortlessly maintained. This mower might be the way out to the difficulties faced by a small scale farmer regarding price and labor requirement. Earlier this machine was tested in farm and was found that the price of mowing using this mower is widely fewer comparing to labor-intensive mowing.
\end{abstract}

Keywords: Field Capacity, Power Transmission, Prototype, Shaft

\section{Introduction}

The livestock division is a substantial backer to Ethiopia's bargain at the nationwide and domestic level. Livestock subsidizes to the incomes of almost $70 \%$ of Ethiopians and accounts for $15-17 \%$ of the total nationwide GDP and $35-49 \%$ of the agricultural GDP [9].

Unquestionably, Ethiopia is stagnant taking the foremost place in its livestock resource prospective related African countries. Yet, due to numerous motives the country has however subjugated from its economic potential for years. Despite the fact that most of the pastorals are gratified of a quantity of cattle they had for a years, their living was not that much enriched. As they are extremely reliant on on foraging lands, pastorals are having no choice to extend the lifetime of their cattle particularly when the famine comes [10].

The report of the Central Statistical Agency [4] provides evidence on fodder usage in pastoral areas of the country; a particular inadequate quantity of improved forage is used by livestock owners. Animal fodder scarcity left overs the leading constraint on herd size and productivity in both the lowlands and highlands.

Employing better-quality forage varieties has numerous benefits. Not merely fixes it increases animal nourishment ensuing in greater producing livestock; it also praises crop production by sustaining soil fertility by nitrogen fixation. Though grazing reduces the fruitfulness of the land, fodder growing increases soil health.

Normal foraging land is also worsening quickly due to great providing, particularly in pastoral areas. Since the ecosystem is very fragile, negligence of properties has fashioned severe difficulties for people in foraging lands.

As foraging force the upsurges biomass production declines. The biomass profit on non-grazed plots diverse from 2.84-4.13 $\mathrm{t} / \mathrm{ha}$, and on foraged plots from $0.84-2.25$ $\mathrm{t} /$ ha Livestock foraging impact on vegetation, soil and hydrology in a tropical highland watershed. Also, the soil damage in foraged plots was beneath the soil acceptance boundary for normal grassland [3]. 
Although much of the forage produced in the country is harvested directly by grazing animals, a small portion is manually harvested and carried to the animal. Making great fineness fodder arises with mowing. Forage crops would be harvested at the correct ripeness to enhance profit and value. Quality in most fodder crops drops rather quickly as the crop enters a propagative stage of development and growth starts too sluggish.

The difficult task in forage preparation is to get this quality level at a time when weather conditions are appropriate for wilting or dehydrating the crop. When substantial rain and poor drying conditions are predicted, it is generally finest to postpone. If the estimate is light rain with satisfactory to good drying conditions to follow, it might be best to last with mowing.

The use of a huge scale machine is unsuitable since it requests high technical experience for action and maintenance and the large investment necessary. So, the use of mechanical fodder mower is suitable for minor holdings, the large investment preventable and low technical process and maintenance knowledge. Fodder mower is a fodder mowing machine which reaps fodder mechanically and lays down the stems, by providing an alternative to using wage to collect in crops by hand at mowing time.

In some areas of Oromia region there is the experience of harvesting the forage crop for cattle feeding. Due to the lack of mechanical forage harvester/mower the activity carried out manually by using sickle which is labor and time intensive work. Manual mowing earns much time and is not effective because it was carried out for 3-4hr at drudgery. Although the land holding is small, it requires numerous days to totally harvest the hay. Additionally, most of the time forage is deteriorated qualitatively and quantitatively on the flied due to lack of timelessness and unsuitable weather conditions. Hence to alleviate the problem, this work was aimed at developing engine operated rotary mower and testing of the performance evaluation.

\section{Materials and Methods}

\subsection{Experimental Site}

The manufacturing of the prototype was conducted at Bako Agricultural Engineering Research Center (BAERC), which is found in West Shewa zone. It lies between $9^{\circ} 04^{\prime} 45^{\prime \prime}$ to $9^{\circ} 07^{\prime} 15^{\prime \prime} \mathrm{N}$ latitudes and $37^{\circ} 02^{\prime}$ to $37^{\circ} 07^{\prime} \mathrm{E}$ longitude in sub-humid agro-ecological zone. The mean lowest and extreme air temperatures are 13.20 and 27.90, correspondingly. The testing and performance evaluation of the mower was done in Gobu Sayo, East Wallaga Zone, Oromia National Regional State, Ethiopia.

\subsection{Material}

The row materials used in constructing the prototype were square pipes, Sheet metals, mild steel shaft, Angle iron, Vbelt, UCP bearings, water pipe and wheel.

\subsection{Design Consideration and Selection}

The design of the pats of the prototype was conducted by taking attention, the specific purposes of each component parts [12]. The major parts are: the cutting unit, power transmission unit and the operating capacity. The design was made as simple as possible to make ease the manufacturing of the prototype.

\subsection{Description of the Rotary Mower}

The rotary mower consists of frame, driving unit, cutting blade, vertically rotating shaft, wheel, handle and engine seat. The supporting frame of the entire assembly was made of angle iron. The pulley on the driving unit transmits power to the cutting blade from the engine crankshaft by twisting the belt to convert the horizontal rotation to vertical blades in rotation. Vertically rotating shaft fasted on the frame with double bearing with housing to hold the blade on horizontal plane. Three wheel brow tires were used carry the machine and for propelling and maneuvering. The handle also used to push and guide the machine while harvesting and transporting the mower.
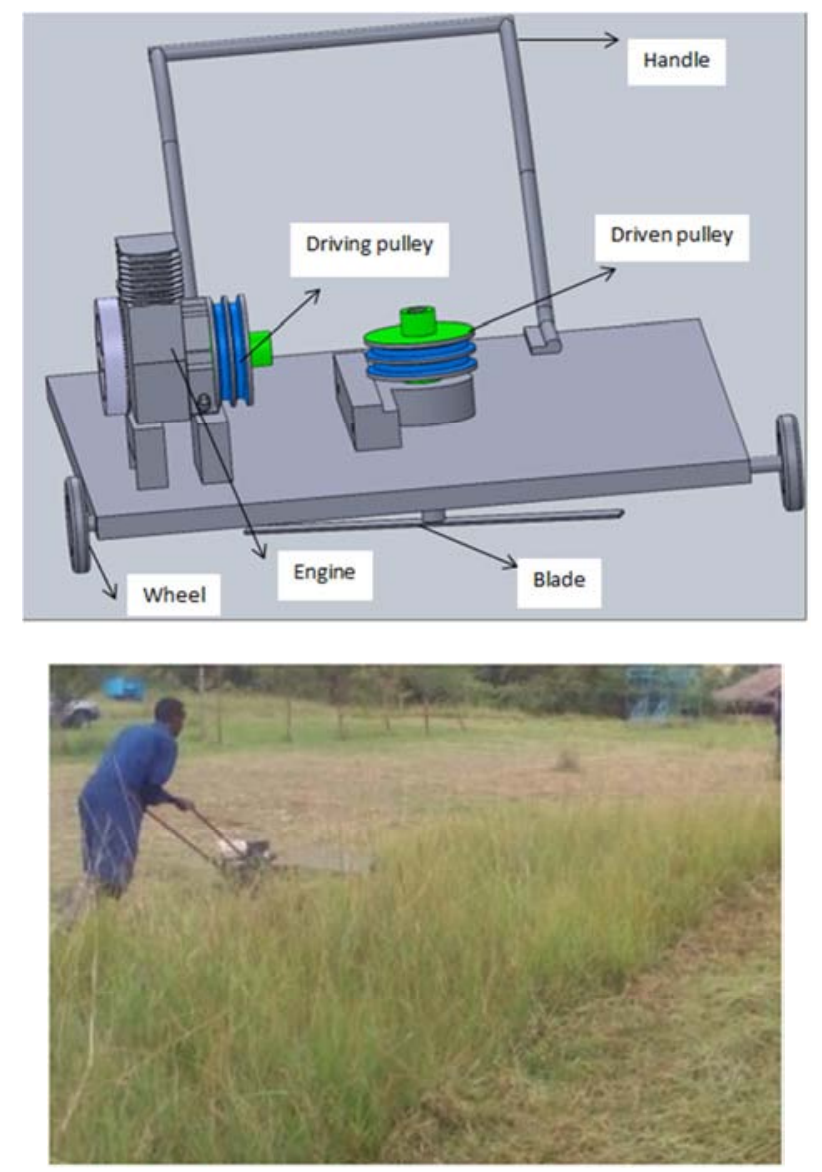

Figure 1. Description of machine component parts and field performance evaluation.

\subsection{Constructions of the Prototype Machine Components}

The fabrication of the prototype machine was carried out on basis of the specification identified and dimensions 
determined for each component. The sketches of the component parts of the mowing machine were presented using CATIA software.

\subsection{Part design}

\subsubsection{Power Transmission Design and Selection}

Limitation to select of $\mathrm{v}$ belt section was raised after the view opinion of smallest pulley diameter. The smallest smaller pulley diameter of $120 \mathrm{~mm}$ was selected for which belt section A was sufficient for power transmission from engine to drum beater. If $\mathrm{v}$ belt of greater thickness (higher section) is used with a comparatively lesser pulley, then the bending stress on the $\mathrm{v}$ belt will be increased, thus decreasing the $\mathrm{v}$ belt lifespan. The cross-sectional area of the belt was calculated by summing of the trapezoidal section where top width is $13 \mathrm{~mm}$; thickness $8 \mathrm{~mm}$ and by calculation, the bottom width was determined as $8 \mathrm{~mm}$. The groove angle of the belt was assumed $34^{\circ}$ which was the average of the range.

$$
\begin{aligned}
& A=\left(\frac{b-x}{2}\right) t+x t \\
& =\left(\frac{13-8}{2}\right) 8+8 x 8=84 \mathrm{~mm}^{2}=8.4 \times 10^{-5} \mathrm{~m}^{2}
\end{aligned}
$$

The mass of the belt per unit length was determined by using the following Eqn. (2).

$$
m=\rho A
$$

Most agricultural machineries have been using rubber belt materials, so that rubber belt has the density of $1140 \mathrm{~kg} / \mathrm{m}^{3}$. Therefore the mass per unit length of the belt determined and valued as follow.

$$
m=1140 \mathrm{~kg} / \mathrm{m}^{3} \times 8.4 \times 10^{-5} \mathrm{~m}^{2}=0.09576 \mathrm{~kg} / \mathrm{m}
$$

The velocity of the $\mathrm{v}$ belt passing over the pulley per unit time was calculated by using eqn. (3) [5].

$$
V=\frac{\pi d_{1} N_{1}}{60}\left(1-\frac{S}{100}\right)
$$

In practical design of $\mathrm{v}$ belt drive are typically grounded on the complete arc contact $\theta$ of the lesser pulley (full load), though the dynamic arc of contact is not known, and the $\mathrm{v}$ belt slips at the lesser pulley first is assumed to be $2 \%$.

$$
V=\frac{3.14 \times 90 m m \times 3000}{60}\left(1-\frac{2}{100}\right)=13.85 \mathrm{~m} / \mathrm{s}
$$

The centrifugal tension of the belt $(\mathrm{Tc})$ is given by Eqn. (4).

$$
T_{C}=m v^{2}
$$

Therefore $T_{C}=0.09576 \mathrm{~kg} / \mathrm{m} x(13.85 \mathrm{~m} / \mathrm{s})^{2}=1.33 N$ Maximum tension in the belt was calculated by using Eqn. (5).

$$
\begin{aligned}
& T_{\text {max }}=\sigma A \\
& T_{\text {max }}=2.8 \mathrm{MPa} x 8.4 \times 10^{-5} \mathrm{~m}^{2}=235.2 \mathrm{~N}
\end{aligned}
$$

Therefore tension in tight side of the belt was calculated as given by Eqn. (6).

$$
\begin{gathered}
T_{1}=T_{\text {max }}-T_{C} \\
T_{1}=235.2 \mathrm{~N}-1.33 \mathrm{~N}=233.87 \mathrm{~N}
\end{gathered}
$$

Coefficient static of resistance among the pulley and the $\mathrm{v}$ belt was estimated by using Eqn. (7) [6].

$$
\begin{aligned}
& \mu=0.54-\frac{0.7}{2.4+V} \\
& =0.54-\frac{0.7}{2.4+9.23}=0.48
\end{aligned}
$$

The Centre distance $(\mathrm{C})$ between the two pulleys is twice the diameter of the larger pulley [8]. The largest pulley diameter was used to determine the center distance between the two pulleys.

$$
\begin{gathered}
C=2 D \\
C=2 \times 120 \mathrm{~mm}=240 \mathrm{~mm}
\end{gathered}
$$

Wrap angle on smaller pulley is determined using Eqn. (9) [1].

$$
\begin{gathered}
\alpha_{1}=180-2 \sin ^{-1}\left(\frac{D_{2}-D_{1}}{2 C}\right) \\
\alpha_{1}=180-2 \sin ^{-1}\left(\frac{120 m m-90 m m}{2 \times 240}\right)=172.84^{0}
\end{gathered}
$$

Tension at slack side was estimated by using Eqn. (10).

$$
\begin{aligned}
& \frac{T_{1}}{T_{2}}=\mathrm{e}^{\mu \alpha_{1}} \\
& \frac{\mathrm{T}_{1}}{\mathrm{~T}_{2}}=4.27 \\
& T_{2}=\frac{233.87 \mathrm{~N}}{4.27}=54.77 \mathrm{~N}
\end{aligned}
$$

Torque on a shaft can be calculated using Eqn. (11).

$$
\begin{aligned}
& T=\left(T_{1}-T_{2}\right) \frac{D}{2} \\
& T=(233.87 \mathrm{~N}-54.77 \mathrm{~N}) x \frac{0.12 \mathrm{~m}}{2}=10.75 \mathrm{Nm}
\end{aligned}
$$

\subsubsection{Shaft Size Determination}

The diameter of the shaft can be calculated according to the theory of maximum shear stress according to [5]. The component forces and reaction forces indicated as shown in the following figure. Hence, shear force and bending moment were determined at critical points as can be seen from the Figure 1. 


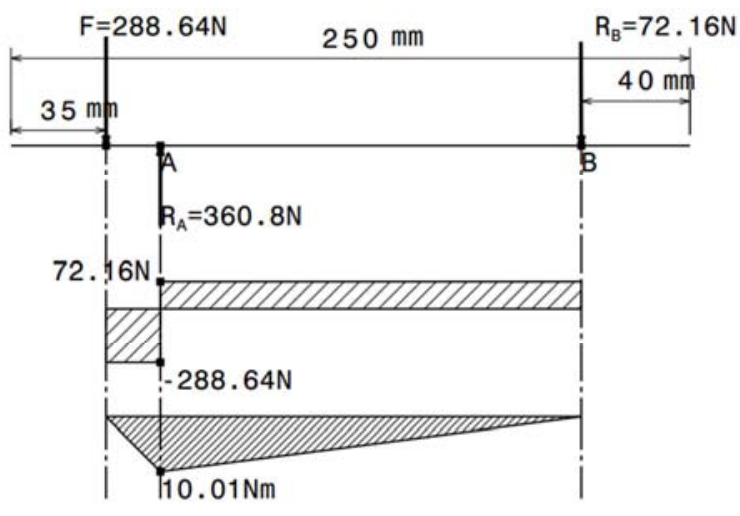

Figure 2. Free body, shear forces and bending moment diagram.
The resultant bending moment with the highest values of $10.01 \mathrm{Nm}$ was selected for design analysis. A bearing catalogue was used to determine ratio of $\mathrm{D} / \mathrm{d}$; and was found to be between 1.20 and 1.50. The values of the constants $C_{b}$ and $C_{t}$ used in Eqn. (12) were obtained from design book as 2.15 for $\mathrm{C}_{\mathrm{b}}$ and from the value of $\mathrm{C}_{t}$ are 1.98. As recommended by Budynas and Nisbett $(2008), K_{b}$ value of 1.20 and $K_{t}$ value of 1.0 were used in Eqn. (12) to estimate the minimum diameter of the shaft. The allowable shear stress $(\mathrm{Sa})$ of $40 \mathrm{MPa}$ for shaft with key way was assumed.

Therefore the shaft was subjected to maximum bending moment at point ' $A$ ' which is $10.01 \mathrm{Nm}$. Hence the size of the shaft was determined as follow [2].

$$
\begin{gathered}
d^{3}=\frac{16}{\pi S_{a}} \sqrt{\left(C_{b} k_{b} M_{b}\right)^{2}+\left(C_{t} k_{t} T\right)^{2}} \\
d^{3}=\frac{16}{3.14 \times 40 \times 10^{6} \mathrm{~N} / \mathrm{m}^{2}} \times \sqrt{(2.15 \times 1.2 \times 10.01)^{2}+(1.98 \times 1 \times 10.75)^{2}}=2.63 \times 10^{-6} \mathrm{~m}^{3} \\
d=14.41 \mathrm{~mm}
\end{gathered}
$$

Since the calculated value of shaft diameter is not available in the standard shaft diameter catalog and the bore diameter of the selected bearings were UCP 206, the shaft diameter of $30 \mathrm{~mm}$ was selected and used conservatively.

\subsubsection{Estimation of Power Required Operating a Mower}

The power required to operate the mower is the sum of the power needed to drive cutting unit and the power needed to overwhelm the drives resistance. The total power $\left(\mathrm{P}_{\mathrm{t}}\right)$ needed for harvesting hay and overcome friction were determined using Eqn. (13 and 14) [1].

$$
\begin{aligned}
P & =2 \pi N T \\
P & =\frac{2 \times 3.14 \times 2100 \times 10.75}{60}=3.17 h p \\
P_{t}= & P+0.10 P \\
P_{t}= & 3.17 h p+0.1 \times 3.17 h p=3.49 h p
\end{aligned}
$$

Therefore, a 5.5 hp model TE 160 having fuel capacity 3.5 liter diesel engine with desired crank speed of $2800 \mathrm{rpm}$ was selected as power source during test and performance evaluation of the prototype.

where:- $\mathrm{P}_{\mathrm{t}}=$ total power required to drive the machine; $\mathrm{T}_{1}=$ tight of side the belt $(\mathrm{N}) ; \mathrm{T}_{2}=$ slack side the belt $(\mathrm{N})$; $\mathrm{V}=$ velocity of belt $(\mathrm{m} / \mathrm{s})$.

\subsection{Prototype Development}

After designing of each component parts of the mower was completed, material type \&amount required for manufacturing (developing) the machine was selected and purchased. The fabrication of the prototype machine was accomplished on basis of the design specification predetermined dimensions for each component. Every part of the machine was produced gradually so that the produced parts was assembled and made ready for test.

\subsection{Performance Evaluation}

Experiments were carried out to evaluate the performance of the harvesting machine to optimize the values of the main operating parameters during the harvesting operation. The assembly of the prototype was taken place at the center and Primary test was conducted. Based on this test results, adjustments of the malfunction parts and fittings were done. During the test and performance evaluation necessary data were collected.

\subsection{Determination of the Grasses Population}

The population of the hay to be harvested can affect the harvesting efficiency, field capacity and the power consumption of the harvesting machine. Before conducting the performance evaluation of the machine the grass population per test plots were determined by counting the numbers of hays found in landed randomly thrown square of $25 \times 25 \mathrm{~cm}^{2}$ which was made of round bar. The square was thrown in each test plot randomly for three time and the average of 140 was obtained.

\subsection{Measurements and Performance Parameter Determinations}

Performance evaluation of the manufactured machine was conducted as follows:

\subsubsection{Field Capacity}

The field capacity is the average rate of harvesting coverage by the machine, grounded upon the total effective operating period of time. It was function of the rate width of the machine [11]. Thus, it can be calculated as given by Eqn. (15) and was determined to be $0.024 \mathrm{ha} / \mathrm{hr}$. 


$$
F . C_{a c t}=\frac{1}{T_{t}}
$$

Where: $F . C_{\text {act }}=$ Actual field capacity $(\mathrm{ha} / \mathrm{hr}), \mathrm{T}_{\mathrm{t}}=$ Total effective operating time (hr. /ha).

\subsubsection{Field Efficiency}

At the end of land head some time was spent due to whirling the machine and other influences like disappointment to use the full width of the implement will be affected for field efficiency. The field effectiveness was calculated as following Eqn. (16) and estimated to be $80 \%$.

$$
F \cdot C_{a c t}=\frac{F \cdot C}{T \cdot F \cdot C} \times 100
$$

\section{Results and Discussion}

An experiment was conducted to develop engine driven mower and determine some performance of the machine. The different parameters were measured which include field capacity and field efficiency.

The prototype was fabricated with the accessible manufacturing methods in the Engineering workshop and tested numerous times to recognize real defects. Later several suitable modifications were made to come up with a reasonable level reliability and field evaluation was done. The total weight of the machine without the engine was 25 $\mathrm{kg}$ and it was manufactured from available materials on local market. The blade must be covered with a covering to direct the clippings, hold the wheels and engine, and for obvious safety reasons. The different parameters were measured which include field capacity, field efficiency and ease of operation. With this regard the field capacity and the field efficiency of the machine was determined to be $0.024 \mathrm{ha} / \mathrm{hr}$ and $80 \%$ respectively.

\section{Conclusion}

The hay mower was manufactured to be affordable and effective to harvest hay crops. The prototype was evaluated on a farm land to obtain its harvesting ability and effectiveness. The test results were successful as the machine performed soundly. It can be concluded that the machine is comparatively affordable and easy to handle. The price of mowing using this prototype is noticeably fewer as relate to labor-intensive mowing. The mowers accessible in market are appropriate for great farms, so this can be the best machine for the farmers with small land.

\section{References}

[1] Akintunde, B. O., Oyawale F. A. and Akintunde, T. Y. 2005. Design and Fabrication of a Cassava Peeling Machine. Nigerian Food Journal 23, 231-238.

[2] ASME. 1995. Design of Transmission Shafting. American Society of Mechanical Engineering, New York, NY USA.

[3] Belay, T. (1992) Farmers' Perception of Erosion Hazards and Attitudes towards Soil Conservation in Gunono, Wolayita, Southern Ethiopia. Ethiopian Journal of Development Research, 14, 31-58.

[4] Ethiopian Central Statistical Agency (ECSA). 2010. Agricultural Sample Survey 2010/2011 Report on Area and Production of Major Leaf sheaths private Peasant Holdings, Meher Season, viewed 26 March.

[5] Gupta, J. K. and Khurmi, R. S. 1984. A Textbook of Machine Design. Eurasia Publishing Revised edition, New Delhi.

[6] Lingaiah, K. 2003. Machine Design Data book, second edition. McGraw -Hill Education: New York.

[7] Nduka, Nwankwojike, B., Odukwe, A., Okay, Agunwamba, C. and Jonah. 2012. Design, Fabrication and Evaluation of Palm Nut-Pulp Separator, Journal of Emerging Trends in Engineering and Applied Sciences (JETEAS) 3 (1): 144-151.

[8] Richard, G. B. and Nisbett, J. K. (2011). Shigley's Mechanical Engineering Design, ninth edition, McGraw-Hill, New York, USA.

[9] GebreMariam, S., Amare, S., Baker, D., Solomon, A. and Davies, R. 2013. Study of the Ethiopian live cattle and beef value chain. ILRI Discussion Paper 23. Nairobi: International Livestock Research Institute.

[10] Ethiopian Herald February 12, 2016.

[11] Kahn, G. S., Kepner, A. and Pepper, J., 1987, July. TEST: A Model-driven Application Shell. In AAAI (pp. 814-818). 